Original Research

\title{
Detecting Urban Growth Patterns and Wetland Conversion Processes in a Natural Wetlands Distribution Area
}

\author{
Yuanbin Cai', Hao Zhang², Wenbin Pan ${ }^{1 *}$ \\ ${ }^{1}$ College of Environment and Resources, Fuzhou University, \\ 2 Xueyuan Road, Shangjie Town, Minhou County 350108, Fuzhou, Fujian Province, China \\ ${ }^{2}$ Department of Environmental Science and Engineering, \\ Fudan University, 220 Handan Road, Shanghai 200433, China
}

Received: May 10, 2015

Accepted: June 20, 2015

\begin{abstract}
Since the $20^{\text {th }}$ century, urbanization has been experiencing a fast developing stage. In two decades, the natural wetlands distribution area (NWDA) of Fuzhou, a forefront city in the West-Taiwan Strait Economic Zone of China, has dramatically changed from an agriculture-dominated landscape to a modern industrialization urban setting. The integrated approach of concentric zone-based analysis and biophysical indices were used to examine the spatial-temporal changes of urban growth patterns and explore historical wetland conversion processes based on remote sensing and geographic information systems in the NWDA from 1989 to 2009. The popular belief was that the wetland was destroyed and converted to developed land, while our study demonstrated wetland losses were conversions to cropland, which revealed that the city growth occupied massive farmland at the initial stage of urbanization. Meanwhile, results demonstrated that the growth pattern can be characterized as dispersed or sprawl in the NWDA during 1989-2009. The large area of developed lands is concentrated within a 3-15 km zone, and the population with high density mainly is concentrated within the scope of 0-9 km areas. Therefore, the best management practice for land use and urban planning should be made to minimize the adverse effects of urbanization in those areas urgently.
\end{abstract}

Keywords: urban growth patterns, land use/land cover (LULC), wetlands conversion paths, geographic information systems (GIS), remote sensing (RS)

\section{Introduction}

Due to the consequence of political and economic reforms, China has experienced a stage of great changes in land use and urban growth since [1-3]. Nowadays, urbanization is still proceeding at staggering speed [4-7]. As a major conversion from natural lands to urban developed lands, urbanization represents an important type of land transformation $[8,9]$ and has been regarded as one of

*e-mail: caiyuanbin82@163.com the biggest challenges of the $21^{\text {st }}$ century [10-12]. Though urban areas cover only $3 \%$ of the earth's land surface, their ecological footprint is much more extensive [1315]. It is widely accepted that it is necessary to protect natural resources [16, 17]. At the same time, it is urgent that urban planning should rely on evidentiary models, valid spatial data, and $3 \mathrm{~S}$ technology $[18,19]$.

Remote sensing has been considered one of the most powerful and effective tools for exploring urban growth patterns and monitoring urban land use/land cover changes $[20,21]$. To derive available information for city managers 
and planners, satellite images can provide high-quality, upto-date, and inexpensive spatial data. Using historical spatial data, one can derive appropriate thematic maps that can help identify the size, direction, and rate of urban construction or the destruction of natural resources overtime $[22,23]$. To this end, it is necessary to consider all natural and human resources such as: vegetation cover, surface and underground water resources, soil cover, wildlife area, and historical cultural landscapes $[24,25]$. This is mainly due to their advantages of large area coverage, repeated viewing capability, and ease of integration with a geographic information system (GIS) [26].

Based on the integration of remote sensing and GIS, the overall objective of this research is to analyze the urban growth patterns and the resulting effects on the environment of the natural wetlands distribution area, Fuzhou city, during the period between 1989 and 2009. With a particular focus on wetlands protection, the study objective was to explore the spatial-temporal changes of natural wetlands in urbanization and how underlying biophysical factors caused the changes by using the historical remote sensing images. Therefore, we summed up the current literature and explained the study area alongside the data and the methods used in the analysis. Finally, we discussed the results of the analysis, and end with a concluding section.

\section{Study Area}

The natural wetlands distribution area (NWDA) is located between latitudes $25^{\circ} 55^{\prime} \mathrm{N}$ and $26^{\circ} 13^{\prime} \mathrm{N}$, and longitudes $119^{\circ} 11^{\prime} \mathrm{E}$ and $119^{\circ} 42^{\prime} \mathrm{E}$ in Fuzhou city (Fig. 1). There is a northern subtropical monsoon climate in this region. The annual temperature is about $20.8^{\circ} \mathrm{C}$ on average, varied widely between $41^{\circ} \mathrm{C}$ in summer 2003 and $-4^{\circ} \mathrm{C}$ in winter 1991. During the May and June flood seasons, annual precipitation was about $33 \%$, which varies from 796.5 to
1,913.6 $\mathrm{mm}$. The Minjiang River as the topographical level is the major river throughout the NWDA. Enclosed by hills and mountains as a basin, Fuzhou is mainly located at an estuarine terrace. Elevation of the area ranges between 1 and $802.4 \mathrm{~m}$, which is $84 \mathrm{~m}$ on average.

As the capital of Fujian Province, Fuzhou consists of five administrative wards (Gulou, Taijiang, Jin'an, Cangshan, and Mawei districtS) and two county-level municipalities (Changle and Minhou counties). The NWDA in Fuzhou has a total population of 2.71 million and covers an area of approximately $1,491 \mathrm{~km}^{2}$. The local GDP per capita is approximately 36,851 RMB Yuan (\$5,395 US) at the end of 2009 and approximately 50.1 percent over the nationwide average (Fuzhou Municipal Bureau of Statistics, 2010) [27]. And this paper takes the research interest concentrate on the urban growth patterns and wetland conversion paths in the NWDA of Fuzhou.

\section{Materials and Methods}

\section{Data Source and Pre-Processing}

Five sets of historical Landsat TM/ETM+ images covering the NWDA were used to develop reliable land use/land cover (LULC) maps (Table 1). Image preprocessing involved layer stack, radiometric calibration, geometric correction, images subset, images mosaic (if necessary), and images mask using the administrative boundary $[28,29]$. All images were cloud-free and acquired during the dry season with clear weather and, therefore, the atmospheric factors could be assumed to be comparable and a correction for atmospheric parameters was not employed in the study. Geometric rectification is critical for producing spatially comparable maps along the time axis [30, 31]. In this study, three dimensional digital topographical maps

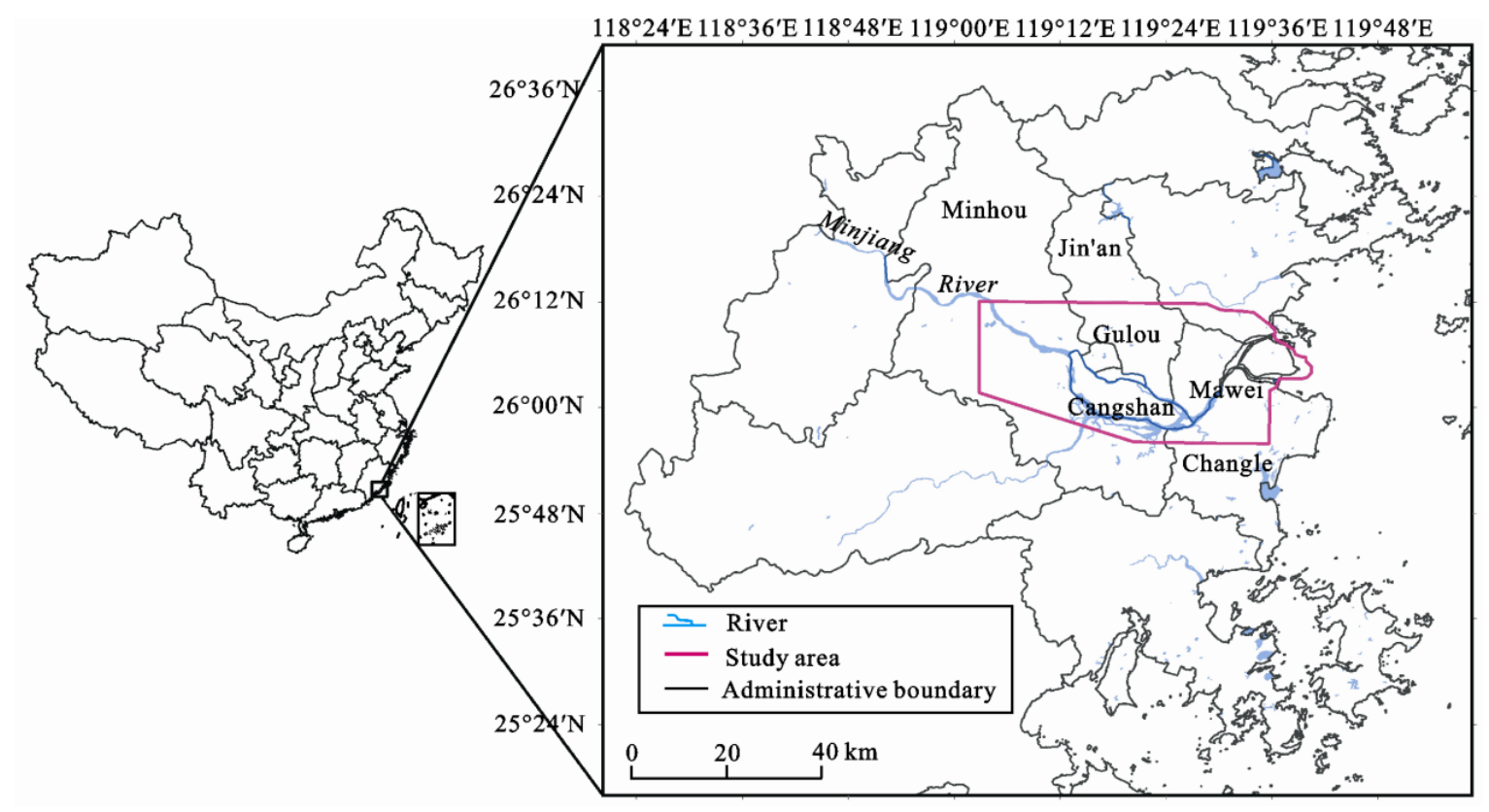

Fig. 1. Location of the study area. 
Table 1. Descriptions of Landsat images used in this study.

\begin{tabular}{|l|c|c|c|c|c|c|c|}
\hline On-board sensor & Path/row & $\begin{array}{c}\text { Acquisition date } \\
\text { (YY-MM-DD) }\end{array}$ & Spectral bands & $\begin{array}{c}\text { Spatial resolution } \\
\text { of TIR band (m) }\end{array}$ & $\begin{array}{c}\text { Geometric registration } \\
\text { RMSE }\end{array}$ & $\begin{array}{c}\text { Overall } \\
\text { accuracy (\%) }\end{array}$ & Kappa \\
\hline Landsat TM & $119 / 042$ & $1989-06-15$ & VNIR-SWIR-TIR & 120 & \pm 0.292 & 78.20 & 0.74 \\
\hline Landsat TM & $119 / 042$ & $1994-05-12$ & VNIR-SWIR-TIR & 60 & \pm 0.261 & 85.16 & 0.81 \\
\hline Landsat ETM+ & $119 / 042$ & $2000-05-18$ & VNIR-SWIR-TIR & 60 & \pm 0.235 & 90.14 & 0.88 \\
\hline Landsat ETM+ & $119 / 042$ & $2006-06-22$ & VNIR-SWIR-TIR & 60 & \pm 0.243 & 86.55 & 0.83 \\
\hline Landsat ETM+ & $119 / 042$ & $2009-06-06$ & VNIR-SWIR-TIR & 60 & Master image & 89.66 & 0.86 \\
\hline
\end{tabular}

RMSE - root mean square error

Table 2. Descriptions of land use/land cover classes of the study area.

\begin{tabular}{|l|l|}
\hline \multicolumn{1}{|c|}{ Land cover class } & \multicolumn{1}{c|}{ Description } \\
\hline Developed land & Mainly including residences, commercial centers, industrial zones, transportation and roads, docks, and harbors \\
\hline Cropland & Arable agricultural land \\
\hline Forest \& shrub & Mainly including natural and semi-natural forestlands, shrub lands, and forest nursery \\
\hline Water & Mainly including rivers, creeks, ponds, and lakes \\
\hline Wetland & $\begin{array}{l}\text { Transition zone between the land and water, mainly including natural or artificial, permanent, or temporary marshes } \\
\text { and peat bog }\end{array}$ \\
\hline Bare land & Land without vegetation cover, mainly including exposed soil and landfill sites \\
\hline
\end{tabular}

(1:25,000 scale) were used for image georeferencing, for digital elevation modeling (DEM), as a base for the LULC map, and for increased accuracy of the overall assessment. The image of 2009 was rectified to the Universal Transverse Mercator (i.e. UTM-20N) projection. The other four images were then calibrated with reference to the master image. More than 100 evenly distributed control points were used in each geometrical correction. These images were geometrically rectified using a second-order polynomial geometrical model and re-sampled by a nearest neighbor algorithm. All of the root mean square errors (RMSEs) are less than one-third of a pixel and reported in Table 1.

This study adopted integrated LULC map retrieval, LULC changes detection, and Shannon's entropy (SE) analysis to detect the spatial-temporal urban growth patterns and wetlands conversion processes in the NWDA. The choice of specific techniques or algorithms to be used depends on the goals of each individual project. ENVI 4.3 software was used in different stages of image processing and for generating various thematic layers. ESRI ARCGIS 10.1 software was used for spatial analysis and map-making.

\section{Land Use/Land Cover Changes}

At the classification stage, land use/land cover types were classified by the use of Landsat TM and ETM+ data from 1989 to 2009. Therefore, the study period covered about 20 years. A uniform, supervised classification was applied to the images $[32,33]$. All of the images were clas- sified by creating accurate polygons as training areas for introducing ideal classes for each image separately. In this study, according to a pre-determined classification scheme of six categories of land covers present within the study area and their image characteristics, a time series of false true color images were produced by combining bands 5, 4, and 3 of the Landsat TM/ETM+ images. Based on our field survey carried out since 1989, the classification scheme of the study area was modified in accordance with the land use classification system by China National Committee of Agricultural Divisions [34-36]. Consequently, six components of the surface features were identified unambiguously, which consisted of forest and shrub, developed land, cropland, water (mainly rivers, channels, and ponds), wetland, and bare land. The descriptions of selected classes are presented in Table 2. Subsequently, the supervised signature extraction with the maximum likelihood algorithm was employed to classify the images [37, 38]. For each image 100 training sites were chosen to ensure that all spectral classes covering each land use and land cover category that were adequately represented in the training statistics [39, 40].

This research is mainly focused on dramatic changes of developed land, wetland, and their interactions. Furthermore, water bodies have very limited coverage and - along with bare land cover - are not discussed further in the results and concluding sections. The maps produced are presented in Fig. 2.

For accuracy assessment of imagery classification we used ancillary data, including land use survey data derived 
from historical aerial photos acquired in 2000 and 2007, a SPOT image with $2.5 \mathrm{~m}$ resolution acquired in 2007 , and the 1:10,000 digitalized topographic map and 1:250,000 digitalized land use maps acquired in 1995, 2000, and 2007. For each image 289 training sites were randomly chosen to ensure all spectral classes covering each land use. After classification, for each image 289 samples were randomly selected to check the accuracy of the classified maps. The overall accuracy of the land use and land cover maps for 1989, 1994, 2000, 2006, and 2009 were $78.20 \%$, $85.16 \%, 90.14 \%, 86.55 \%$, and $89.66 \%$, respectively. Accordingly, the Kappa indices for 1989, 1994, 2000, 2006, and 2009 were $0.74,0.81,0.88,0.83$, and 0.86 , respectively, with an average of 0.82 . These indices meet the recommended value by Jassen et al. [41, 42]. Therefore, these data were available for further study.

A cross-tabulation detection analysis was employed to perform LULC changes [43]. The land use change matrix, which showed quantitative data of the overall land use and land cover changes during 1989 and 2009 in the study area, was observably produced. Based on the six main types of gains and losses in each category indicated by the change matrix (Table 3), land use transfer images and land use transfer matrix for each category were also produced (Table 4).

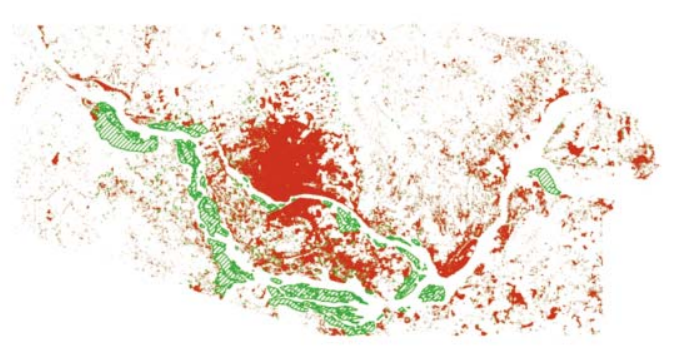

1989

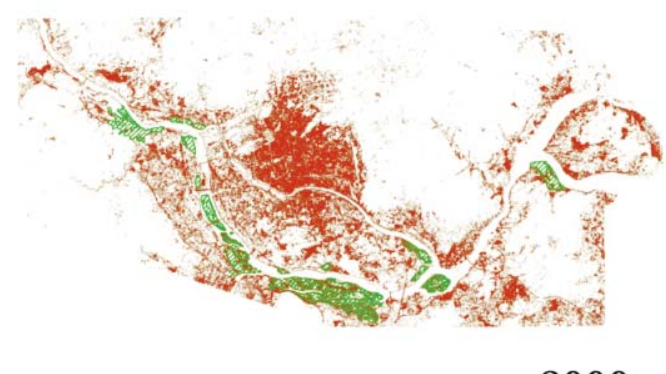

2000
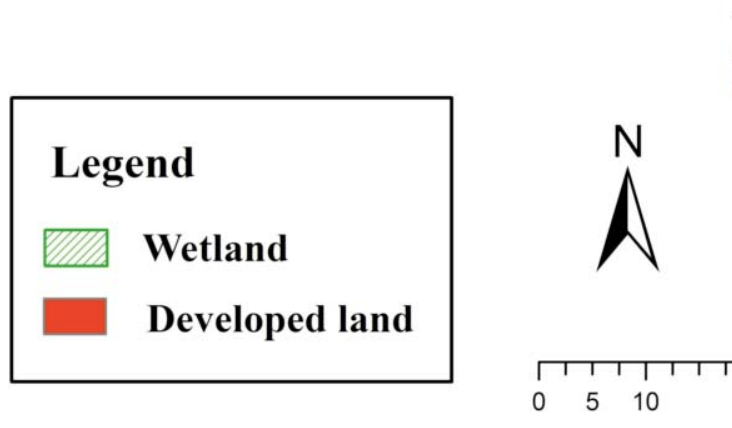

In the next step, we make use of Shannon's entropy, a method widely applied in studies of urban sprawl. Shannon's entropy is an indicator of spatial concentration or dispersion and can be applied to any geographical variable [44]. The method may reveal the orientation and configuration of spatial patterns and it is also convenient, as it can be applied to spatial variables within a GIS [14, 45, 46].

The calculation assumes that an urban area is divided into $\mathrm{n}$ zones, and a variable $X$ takes on a value $X_{i}$ for any zone $i \in\{1,2, \ldots, n\}$. Shannon's entropy $\left(S E_{n}\right)$ is computed as follows:

$$
S E_{n}=\sum_{i}^{n} P_{i} \log \left(1 / P_{i}\right)
$$

...where $P_{i}$ here is the proportion or probability of the variable occurring in zone $i$ and is given by:

$$
P_{i}=X_{i} / \sum_{k}^{n} X_{k}
$$

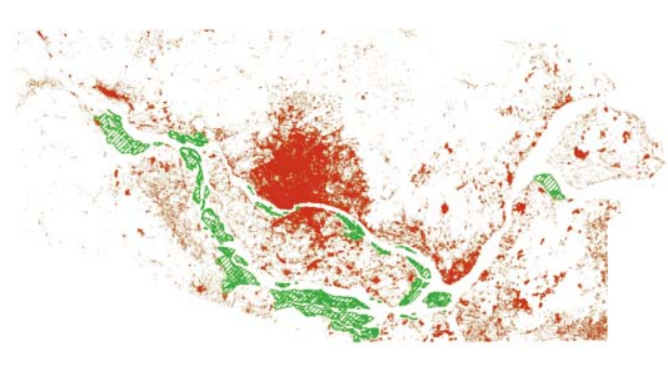

1994
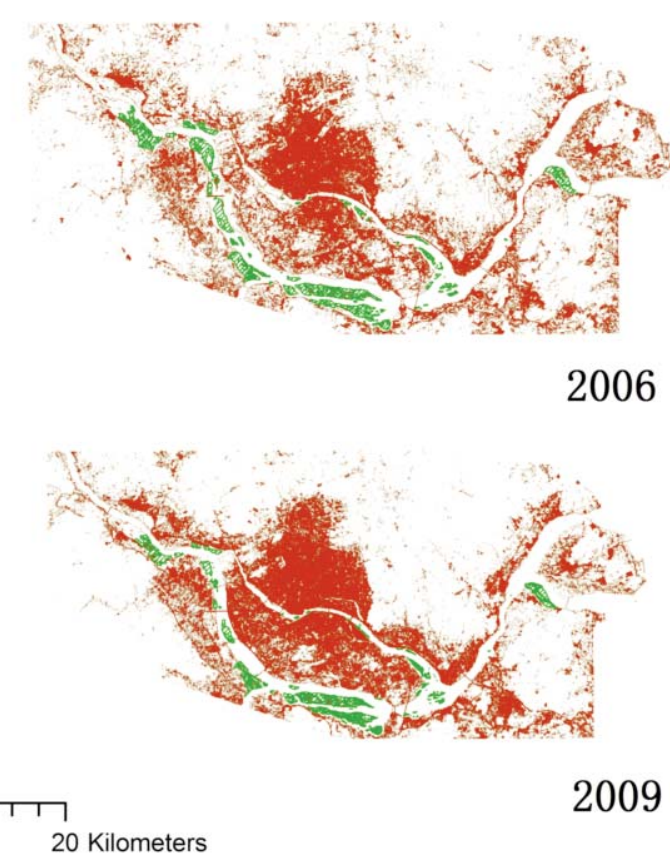

Fig. 2. Developed land and wetland maps for 1989, 1994, 2000, 2006, and 2009. 
Table 3. Net gain-loss and annual change rates of land cover types in the study area.

\begin{tabular}{|l|c|c|c|c|c|c|c|c|c|c|}
\hline \multirow{2}{*}{ Land cover type } & \multicolumn{2}{|c|}{$1989-2009$} & \multicolumn{2}{c|}{$1989-1994$} & \multicolumn{2}{c|}{$1994-2000$} & \multicolumn{2}{|c|}{$2000-2006$} & \multicolumn{2}{c|}{$2006-2009$} \\
\cline { 2 - 13 } & NGL & ACR & NGL & ACR & NGL & ACR & NGL & ACR & NGL & ACR \\
\hline Developed land & 232.60 & 11.63 & 55.09 & 11.02 & 64.17 & 10.70 & 51.66 & 8.61 & 61.68 & 20.56 \\
\hline Cropland & -185.49 & -9.27 & -13.37 & -2.67 & -14.88 & -2.48 & -80.21 & -13.37 & -76.73 & -25.58 \\
\hline Forest and shrub & 7.17 & 0.36 & -22.57 & -4.51 & -6.55 & -1.09 & 33.18 & 5.53 & 3.11 & 1.04 \\
\hline Water & 1.01 & 0.05 & -5.83 & -1.17 & -43.23 & -7.21 & 34.94 & 5.82 & 15.13 & 5.04 \\
\hline Wetland & -54.84 & -2.74 & -19.83 & -3.97 & -1.93 & -0.32 & -27.33 & -4.56 & -5.75 & -1.92 \\
\hline Bare land & -0.45 & -0.02 & 6.82 & 1.36 & 2.39 & 0.40 & -12.23 & -2.04 & 2.56 & 0.85 \\
\hline
\end{tabular}

$\mathrm{NGL}$ - net gain-loss $\left(\mathrm{km}^{2}\right), \mathrm{ACR}$ - annual change rate $\left(\mathrm{km}^{2} /\right.$ year$)$, and negative value shows net loss of area $\left(\mathrm{km}^{2}\right)$.

Table 4. Land use transformation matrix in 1989-2009 $\left(\mathrm{km}^{2}\right)$.

\begin{tabular}{|l|c|c|c|c|c|c|c|}
\hline \multicolumn{1}{|c|}{ Class } & Developed land & Cropland & Forest and shrub & Water & Wetland & Bare land & $\sum 1989$ \\
\hline Developed land & 137.19 & 2.87 & 8.63 & 0.82 & 0.22 & 1.43 & 151.16 \\
\hline Cropland & 113.11 & 30.80 & 180.70 & 8.47 & 0.03 & 2.33 & 335.43 \\
\hline Forest and shrub & 98.95 & 85.24 & 574.57 & 3.50 & 0.00 & 2.38 & 764.64 \\
\hline Water & 14.31 & 5.33 & 1.66 & 130.15 & 2.97 & 1.34 & 155.77 \\
\hline Wetland & 17.68 & 24.91 & 4.63 & 9.76 & 15.60 & 1.39 & 73.96 \\
\hline Bare land & 2.53 & 0.79 & 1.62 & 4.08 & 0.30 & 0.91 & 10.22 \\
\hline$\sum 2009$ & 383.76 & 149.94 & 771.81 & 156.78 & 19.12 & 9.77 & $1,491.18$ \\
\hline
\end{tabular}

The rows and columns contain data of 1989 and 2009, respectively.

For the purposes of our study, zones are defined as concentric circles around the administrative center of the city center. The value of entropy varies between zero, for a totally concentrated distribution, and $\log (n)$, for a totally dispersed distribution of $X$. Eq. (1) defines what is known as absolute entropy [47]. However, we used relative entropy, which is considered to be easier for judgment, with values varying between 0 for total concentration and 1 for total dispersion in this study. Relative Shannon's entropy $(S E)$ is defined as:

$$
S E=\sum_{i}^{n} P_{i} \log \left(\frac{1}{P_{i}}\right) / \log (n)
$$

Shannon's entropy method is effective and convenient in identifying whether the pattern of land development is compact or dispersed. And other methods, such as fractal dimension, cannot identify changes in orientation and configuration [48].

\section{Statistical Zone-Based Analysis}

For the purposes of the present study, 13 concentric circles (12 concentric zones) were determined, each with the radii of two consecutive circles differing by $3 \mathrm{~km}$. The center of the circles was the administrative center of Fuzhou.
A zone was defined as the intersection of the city shape with the ring specified by two consecutive concentric circles. The operation was performed in ArcGIS for all the available images of the city (Fig. 3).

\section{Results and Discussion}

\section{LULC Conversion Characteristics and Urban Growth Patterns}

Apparently, an exponential growth in developed land was observed across the study period (Table 3 ). In fact, there were increasing trends for developed land and forest and shrub during the past 20 years. The change of developed land was most significant, increasing by $232.60 \mathrm{~km}^{2}$ with an average changing rate of $11.63 \mathrm{~km}^{2} / \mathrm{yr}$, followed by forest and shrub with an increasing rate of $0.358 \mathrm{~km}^{2} / \mathrm{yr}$. In contrast, both wetland and cropland experience remarkably decreased. Cropland decreased by $185.49 \mathrm{~km}^{2}$ during the study period, followed by wetland, which decreased on average by $2.74 \mathrm{~km}^{2} / \mathrm{yr}$ (Table 4). Simultaneously, the areal extents of water and bare land slightly varied and nearly stabilized. Furthermore, together with Tables 3, 4, and Fig. 2, several prominent features for changes in LULC were detected across different periods. It can be seen that developed land is always the dominant receiver for growing 


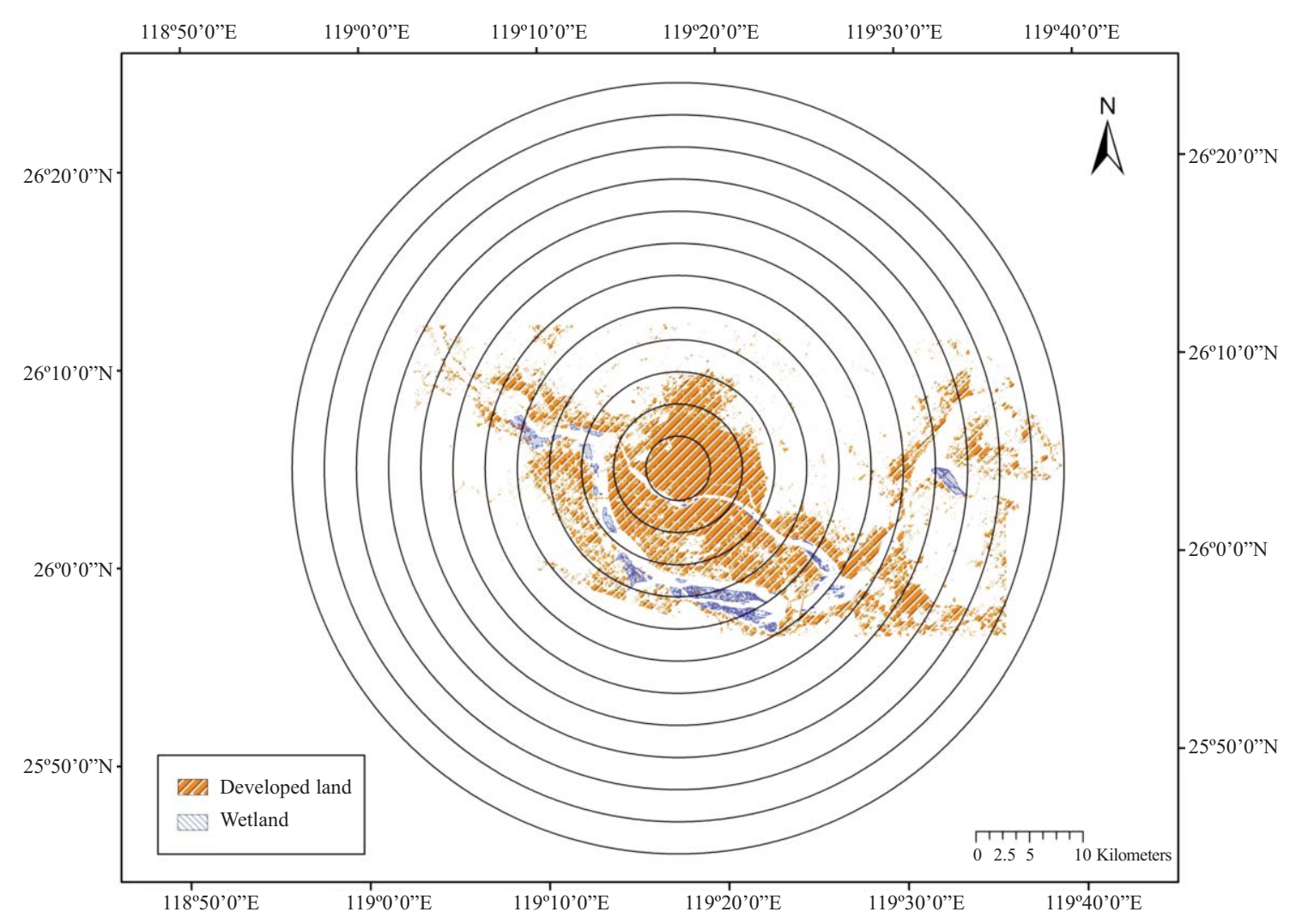

Fig. 3. Twelve buffer zones around the administrative district of Fuzhou for 2009.

extent in itself, followed by forest and shrub. Spatially, generated maps and field observations also revealed that new urban growth was mostly concentrated in northwestern parts along the main stream of the Minjiang River. This is because of the city's geographical position and geological features (Figs. 1, 2). Fuzhou is limited to the north by the Gushan Mountains, and to the southeast by the Taiwan Strait. Thus, the only remaining places for new construction were the northwestern parts of Fuzhou plain and along major roads and transportation routes.

As discussed earlier, relative Shannon's Entropy is a well-known and effective method for the identification of sprawled growth [48]. Based on 12 concentric zones, the calculated relative Shannon's entropy values were 0.93, $0.95,0.95,0.94$, and 0.93 in $1989,1994,2000,2006$, and 2009 , respectively, which represented a dispersed development in urbanization. And the urban growth pattern can be characterized as dispersed or sprawl during 1989-2009. Obviously, the developed lands such as vast stretches of residences, economic development zones, and supporting traffic facilities were dramatically developed within 3-15 km concentric zone during the past 20 years (Fig. 4). Herein, it is noteworthy that the new town development plan at Cangshan District, which had a large area of crop-

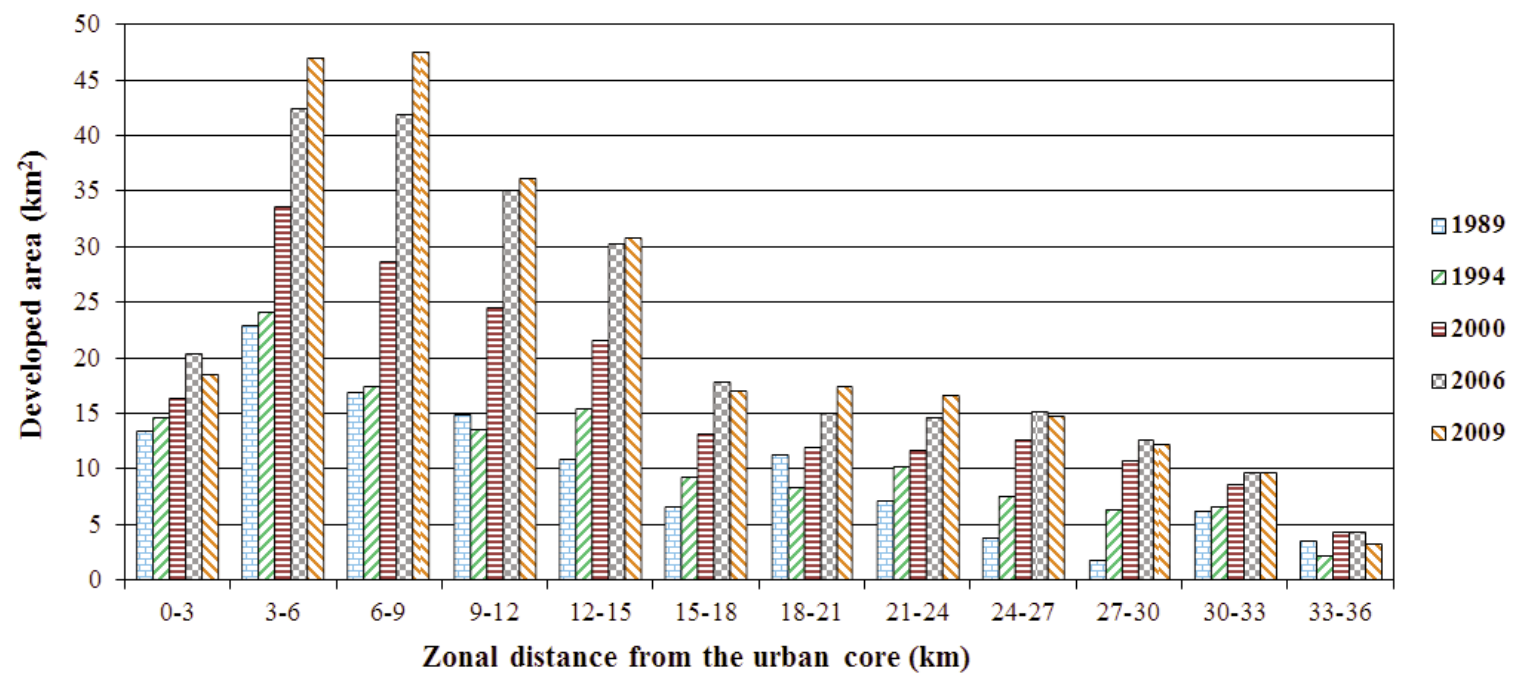

Fig. 4. The developed area in different concentric rings during 1989 and 2009. 


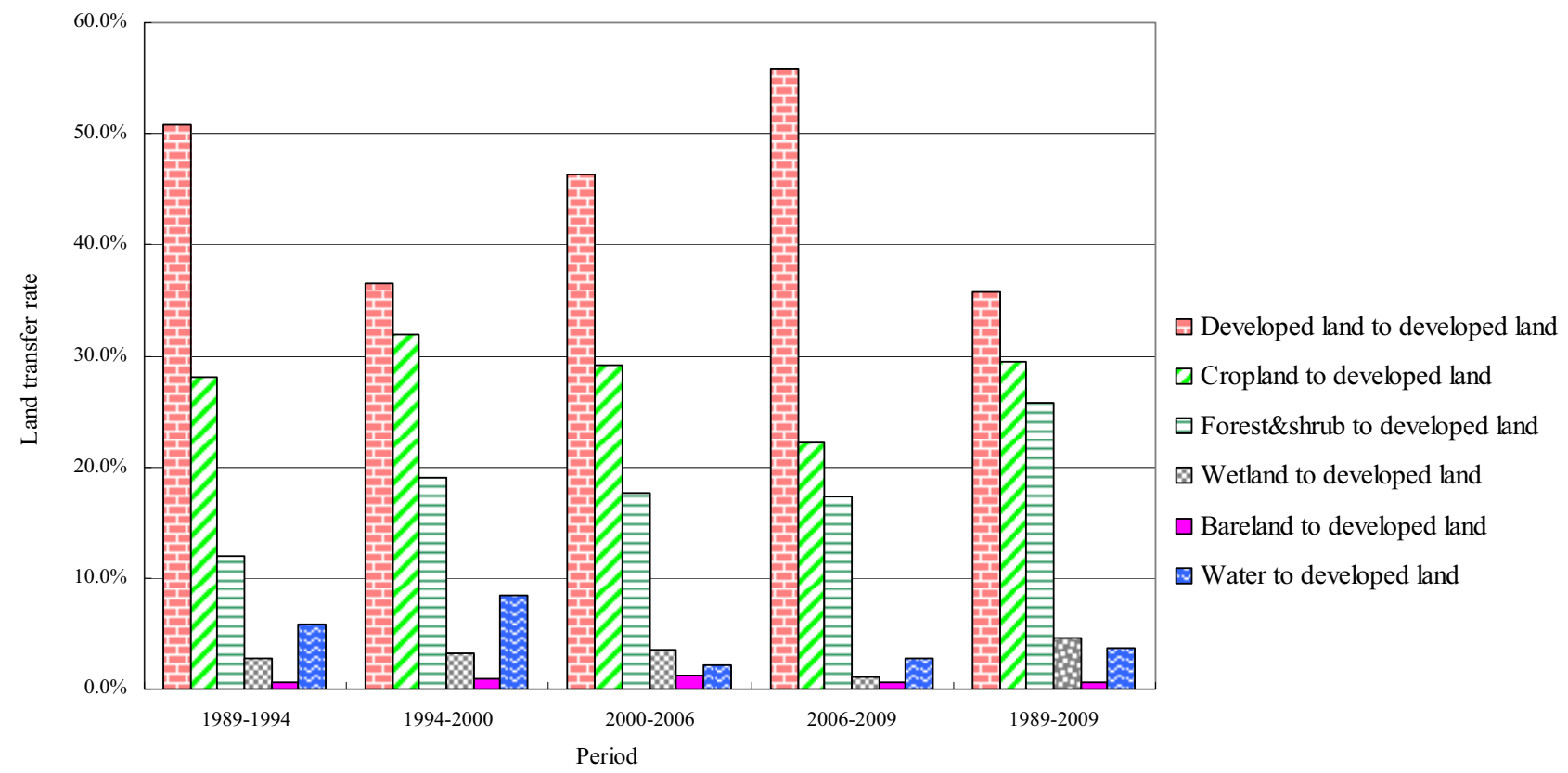

Fig. 5. Land use conversion paths among different land cover types during 1989 and 2009.

land and aims at developing the new downtown of Fuzhou City, has been recently implemented and would further accelerate urban expansion. Meanwhile, as observed in Fig. 5, considerable cropland and forest and shrub were converted to urban developed land. According to the exploration on the source of developed land or the sink of other land cover types, the area of developed land converted with non-vegetated area (i.e. developed land, bare land, and water area) always seemed lower, compared to the conversion with other vegetation types (i.e. cropland, wetland, or forest and shrub land) (Fig. 5, Table 2).

Based on concentric zone analysis supported by GIS and RS technology, the distribution of population density was performed from 1989 to 2009 in Fig. 6. As witnessed, the population with high density mainly concentrated within the scope of 0-9 $\mathrm{km}$ areas. Generally, we noticed a decreasing trend from the city center to the surrounding areas. In other words, the population density was shown as concentrated characteristics that differed from the urban growth pattern during 1989 to 2009.

\section{Wetlands Conversion Paths in the NWDA}

The wetlands in the NWDA were recognized as the key shelter for internationally well-known waterfowl and fishes. On the whole, the net gains of developed land from wetland and water bodies are much lower than cropland, forest, and shrub (Table 3). According to our study on conversion source of developed land, most urban growth in the NWDA was not directly from wetland. In fact, wetland losses in the study area were the conversions to cropland, which revealed that the city growth occupied massive farmland at the initial stage of urbanization (Fig. 7).

On the other hand, net loss of wetland was remarkably high within their corresponding land categories (Table 3). Based on our field survey, we found newly emerging aban-

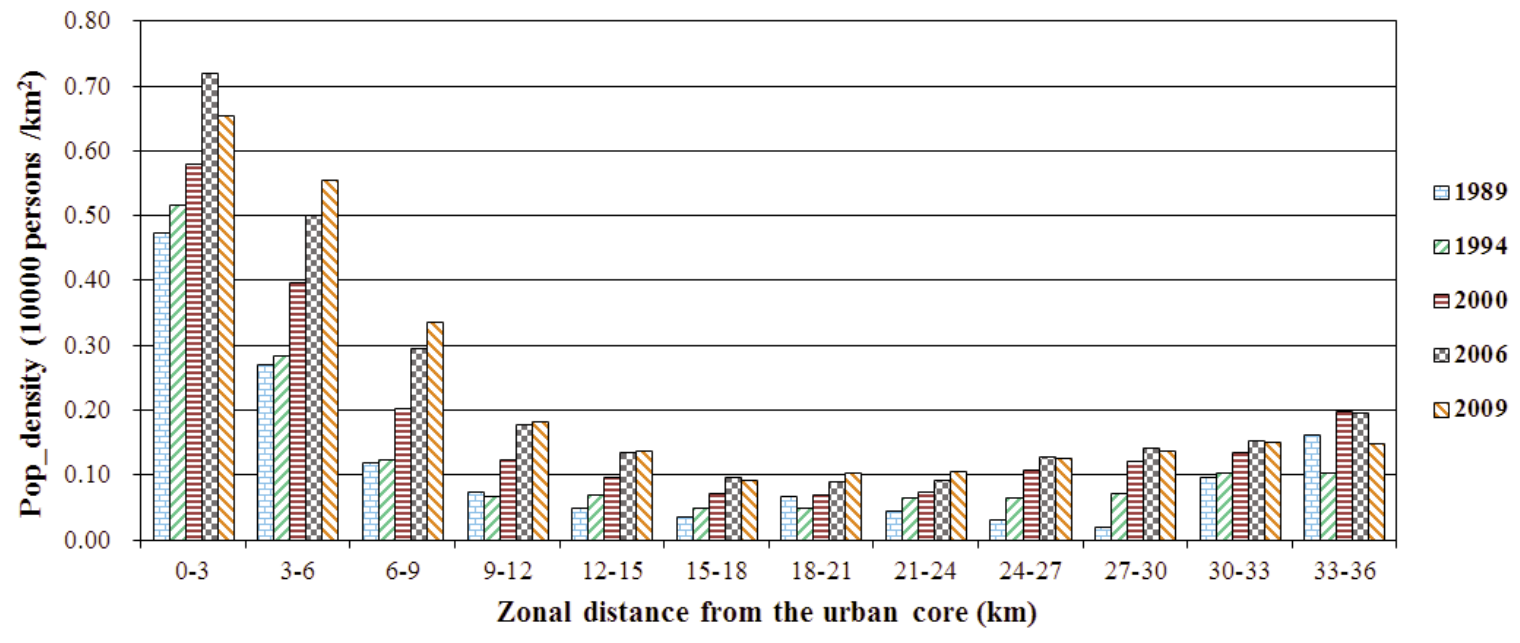

Fig. 6. The population density in different concentric rings during 1989 and 2009. 
doned farmland. To a large degree, this occurred due to much lower economic return of agricultural production when compared with as well as employment in commercial and industrial enterprise. Thus, the abandoned farmland shifted to developed land, and forest and shrub gradually.

\section{Implications for Urban Planning and Protection of Natural Wetlands}

The past 20 years witnessed prosperous economic growth and expansion of developed land in Fuzhou. As a result of complex interactions among environmental, social, political, and historical factors, a variety of driving forces could impact LULC and further interact dynamically to produce different sequences and trajectories [49, 50]. Despite the correspondence in the growth of social economy and developed areas, the detailed story was different over 20 years.

During 1989 to 1994, developed land increased by $7.29 \%$, from $151.16 \mathrm{~km}^{2}$ to $206.25 \mathrm{~km}^{2}$. Meanwhile, the GDP increased by $35 \%$, which revealed the development peak in the NWDA of Fuzhou. In other words, the living standard of people continued to be improved. Therefore, at this first stage, most of the newly emerging developed land expanded in the city proper. And the reclamation of enclosed tidal land sprang up. As a result, the area of wetland greatly decreased by $5.36 \%$, which directly caused the natural wetland degradation in the NWDA. Moreover, a free trade zone and High Technology Park were built in succession.
During 1994 to 2000 the development of the study area was slower than the former stage. Developed land in the NWDA increased by $64.18 \mathrm{~km}^{2}$. Topographically, the Minjiang River limited spatial expansion of the city proper. Besides, urban regeneration slowed down due to urban planning policy constraints until 1999, when 'Fuzhou Urban Development Planning' was formally authorized by the State Council of China. Therefore, the overall pattern for development of the NWDA remained nearly unchanged.

After 2000, the development of the region was greatly affected by tidal and typhoon effects, resulting in an inundation of the wetland system and the removal of many plant communities. The super typhoon called Dragon King hit the NWDA in 2005. After that, large areas of bare land along river channels were flooded and many flood control projects appeared. Ultimately, spatial growth of developed land in the NWDA was relatively lower.

As the development of urban structure and socio-economic composition, the change of urban landscape became more sophisticated and undoubtedly influenced by anthropogenic factors. As a result, developed land abruptly increased at the cost of converting from other types. To satisfy the immediate demands of people, land conversion from one type to another and land-cover modification by anthropogenic management largely changed much of the earth's surface [51, 52]. For example, after 2006, many cities of China are experiencing the real estate craze. Fuzhou as one of the coastal frontier open cities in China is

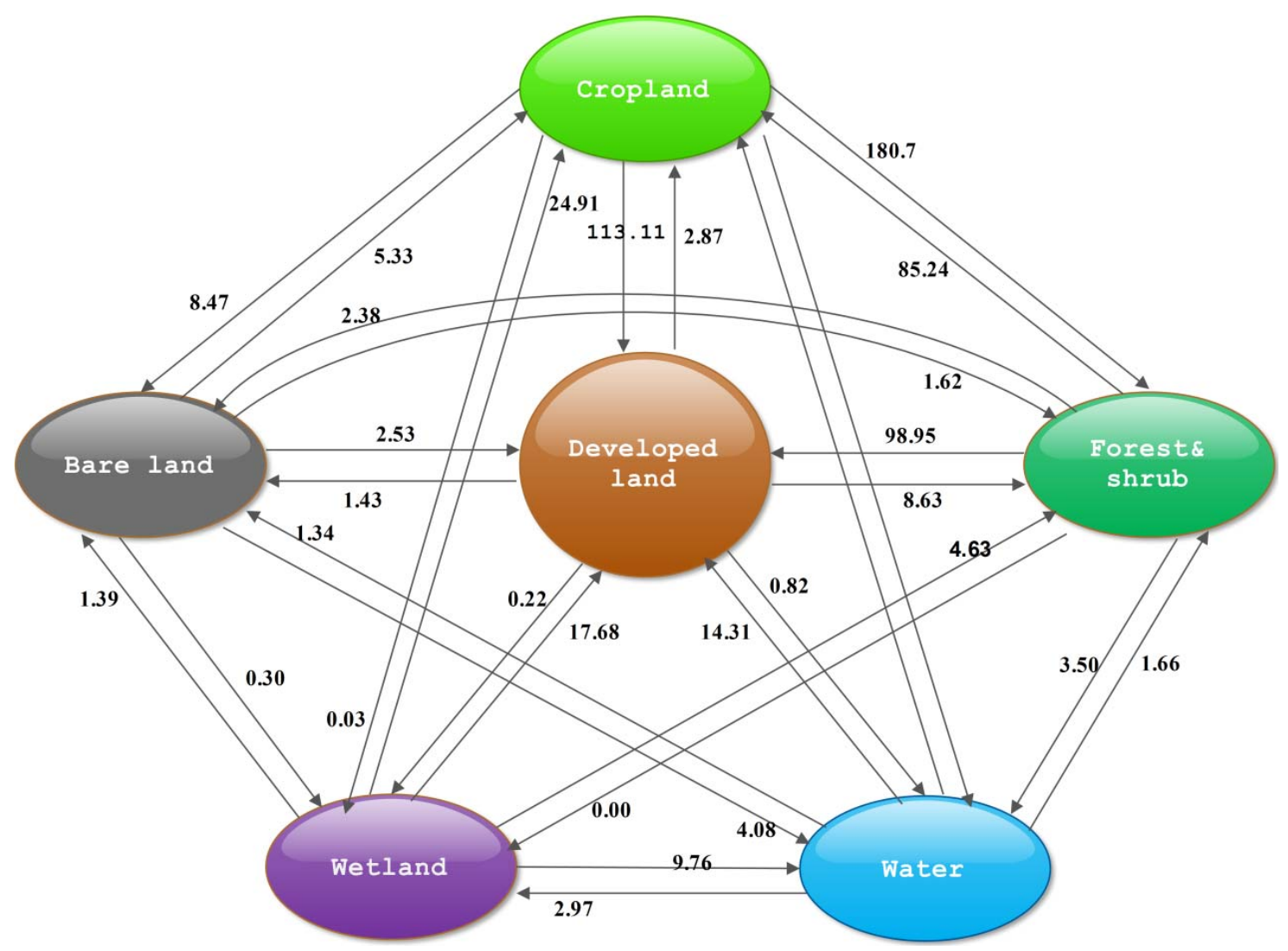

Fig. 7. Land use conversion paths among different land cover types during 1989 and 2009. 
leading the booming market in developed land transformation and real estate development. Naturally, the expansion of the developed land in the NWDA became faster. Furthermore, the state council issued a series of policies that support the great-leap-forward development of the west-strait economic zone. This resulted in the establishment of intensive industrial parks, settlements, college parks, commercial facilities, and expressway systems linking the city proper with suburban and rural areas. Therefore, both urban and satellite towns in suburban areas expanded remarkably.

On the macro level, it is widely accepted that the objective of a state political system must serve economic development during China's recent transition from a planned economy to a market-oriented economy. Owing to the "1992 Consensus within the framework of one-China" released by Chinese mainland's Association for Relations Across the Taiwan Strait (ARATS) and Taiwan's Straits Exchange Foundation (SEF) in Hong Kong in 1992, the dream for business across the straits has come true. Since 2006 both the mainland and Taiwan have called for closer cross-strait economic cooperation, and such cooperation has gained momentum. Therefore, Fuzhou benefited greatly from the political favorites, witnessed with prosperous investments abroad. Thereafter, the state council of China released a series of policies to support the development of the economic zones around the city proper and along the Minjiang River. Undoubtedly, the Minjiang River is a lifeline in the NWDA, and also the lifeblood of the local economy. In order to protect the river and to conserve soil and water, a series of countermeasures have been adopted by local residents. At the same time, uncontrolled human activities may also lead to unreasonable land use/land cover changes near the river line. That was why the wetlands degradation occurred along the Minjiang River over 1989 to 2009 .

Admittedly, the government has a consciousness of environmental protection; however, space in developed areas is limited, and the afforestation had to take place surrounding the developed areas. Thus, in the long term much attention should be paid for the protection in key areas of the NWDA (i.e. 3-15 km zone), especially on the wetland and cropland. The key areas can be recognized more simply in the combination of GIS and RS technology, then the best management practice (BMP) should be adopted immediately to prevent wetland degradation. Besides, it is noteworthy that coordination between the administrative agencies should be strengthened to balance for sustainable development.

\section{Conclusion}

This study examined the urban growth and explored the wetlands conversion paths in the NWDA of Fuzhou - one of the most important historical, cultural, and commercial cities in southeastern China. Remote sensing and GIS techniques were used to monitor the dynamic phenomenon of urbanization with the help of satellite images and census data for the region.
In the NWDA of Fuzhou, developed land is always the dominant receiver for growth, followed by forest and shrub. Urban developed land expansion has largely been shaped by terrain, such as mountains and rivers, and social factors such as population growth and migration. Moreover, rapid development of infrastructures, facilities, industrial parks, and urban and rural settlements along the Minjiang River have resulted in the northwestern expansion of developed land. Despite the popular belief that the wetlands were destroyed and converted to developed land, this study demonstrated that most urban growth in the NWDA did not stem directly from wetlands at the initial stage. In fact, wetland losses in the study area were conversions to cropland, which revealed that the city growth occupied massive farmland at the initial stage of urbanization. And the conversion of cropland to developed land, however, has been a more recent phenomenon. Furthermore, the conversion in nonvegetated areas always seemed lower than in areas with other vegetation types.

Meanwhile, this study demonstrates that the growth pattern of the NWDA can be considered as a classic case of sprawled growth during 1989-2009. This pattern of growth is also supported by calculations of relative Shannon's entropy, a valid methodology for the identification of sprawl. On the other hand, geographical position and geological features limited the city to a northwestern development along the main stream of the Minjiang River. Based on the concentric zones analysis, the large area of developed lands concentrated within 3-15 km zones and the population with high density mainly concentrated within the scope of 0-9 $\mathrm{km}$ areas during the past 20 years.

Until now, the observed ecological degradation such as loss of wetland and cropland due to heavy pressure of rapid urbanization have greatly impaired the capacity of the city to meet the challenges presented by international competition and provide sustainable environment. Therefore, scientific and rational policies for land use and urban planning must be made to minimize the adverse effects of urbanization. Furthermore, coordination among the administrative agencies should be urgently strengthened to balance the conflicts between ecological conservation and urban development to make sure of sustainable land use.

On methodological grounds, this study reinforces the high value of remote sensing in urban studies and ecological monitoring. With the increasing significance of ecological studies in planning, it is important that similar research be undertaken for other cities in China, an environmentally sensitive country. With regards to Fuzhou, further research is needed to develop accurate, predictive growth models based on different scale zones. Using satellite images, it is possible to predict future urban growth and its impact on wetlands degradation by using spatial statistical models, cellular automata, or artificial neural networks. As with any other analysis, the performance of such models is dependent on the quality and type of the data available for parameterization, calibration, and validation. However, when using such models, one has the flexibility to investigate a variety of possible growth scenarios. 


\section{Acknowledgements}

This study was financed by the Scientific Research Project of Fuzhou University (Grant No. 510097) and the National Natural Science Foundation of China (Grant No. 41171432). The authors are grateful to our colleagues at Fudan University, Fuzhou Research Academy of Environmental Sciences, and Fuzhou Municipal Planning Bureau for their generous assistance in field surveys and data collecting. We would like to thank the international Scientific Data Service Platform operated by the Computer Network Information Center and the Chinese Academy of Sciences, which generously provide online technical service for repairing Landsat ETM+ SLC-off products. Also, special thanks to the Center for Earth Observation and Digital Earth, Chinese Academy of Sciences, who kindly provide available Landsat TM/ETM+ imagery within the framework of a sharing program for earth observation data.

\section{References}

1. HU Y., BAN Y., ZHANG Q., LIU J. The trajectory of urbanization process in the Yangtze River delta during 1990 to 2005. Jt. Urban Remote Sens. Event (JURSE), 18, 2009.

2. SU S., JIANG Z., ZHANG Q., ZHANG Y. Transformation of agricultural landscapes under rapid urbanization: a threat to sustainability in Hang-Jia-Hu region, China. Appl. Geogr. 31, (2), 439, 2011

3. CHEN M., LIU W., TAO X. Evolution and assessment on China's urbanization 1960-2010: under-urbanization or over-urbanization? Habitat Int. 38, 25, 2013.

4. DENG X., HUANG J., ROZELLE S., UCHIDA E. Growth, population and industrialization, and urban land expansion of China. J. Urban Econ. 63, (1), 96, 2008.

5. CHEN M., LU D., ZHA L. The comprehensive evaluation of China's urbanization and effects on resources and environment. Journal of Geographical Sciences 20, (1), 17, 2010.

6. BOTEQUILHA-LEITÃO A. Eco-polycentric urban systems. An ecological region perspective for network cities. Challenges 3, 1, 2012.

7. ZHANG N., GAO Z., WANG X., CHEN Y. Modeling the impact of urbanization on the local and regional climate in Yangtze River Delta, China. Theor. Appl. Climatol. 102, (34), 331, 2010.

8. GONG C., CHEN J., YU S. Spatiotemporal dynamics of urban forest conversion through model urbanization in Shenzhen, China. Int. J. Remote Sens. 32, (24), 9071, 2011.

9. KAZA N. The changing urban landscape of the continental United States. Landscape Urban Plan. 110, 74, 2013.

10. SCHWEITZER F. Cities and complexity: understanding cities with cellular automata, agent-based models, and fractals. Nature. 441, 815, 2006.

11. TIAN G., JIANG J., YANG Z., ZHANG Y. The urban growth, size distribution and spatio-temporal dynamic pattern of the Yangtze River Delta megalopolitan region, China. Ecol. Model. 222, (3), 865, 2011

12. DENG J.S., WANG K., HONG Y., QI J.G. Spatio-temporal dynamics and evolution of land use change and landscape pattern in response to rapid urbanization. Landscape Urban Plan. 92, (3), 187, 2009.
13. GONG P., LIANG S., CARLTON E.J., JIANG Q., WU J., WANG L., REMAIS J.V. Urbanization and health in China. Lancet. 379, (9818), 843, 2012.

14. SARVESTANI SABET M., AB LATIF I., KANAROGLOU $P$. Three decades of urban growth in the city of Shiraz, Iran: A remote sensing and geographic information systems application. Cities. 28, 320, 2011.

15. WU J., JENERETTE G. D., BUYANTUYEV A., REDMAN C. L. Quantifying spatiotemporal patterns of urbanization: the case of the two fastest growing metropolitan regions in the United States. Ecological Complexity 8, (1), $1,2011$.

16. AB LATIF BIN I., SARVESTANI SABET M. Urban sprawl pattern recognition using remote sensing and GIS, case study Shiraz City, Iran. In Proceedings of urban remote sensing joint event, Shanghai, China. 20-22, 2009.

17. KIM S., ROWE P.G. Does large-sized cities' urbanisation predominantly degrade environmental resources in China? Relationships between urbanisation and resources in the Changjiang Delta Region. Int. J. Sustain Dev. World Ecol. 19, (4), 321, 2012.

18. GUO L., WANG D., QIU J., WANG L., LIU Y. Spatio-temporal patterns of landuse change along the Bohai Rim in China during 1985-2005. Journal of Geographical Sciences 19, (5), 568, 2009.

19. FURBERG D., BAN Y. Satellite monitoring of urban sprawl and assessment of its potential environmental impact in the Greater Toronto area between 1985 and 2005. Environ. Manage. 50, (6), 1068, 2012.

20. HEPINSTALL-CYMERMAN J., COE S., HUTYRA L. R. Urban growth patterns and growth management boundaries in the Central Puget Sound, Washington, 1986-2007. Urban Ecosystems. 16, (1), 109, 2011.

21. JAIN S., KOHLI D., RAO R.M., BIJAKER W. Spatial metrics to analyse the impact of regional factors on pattern of urbanization in Gurgaon, India. Journal of the Indian Society of Remote Sensing. 39, (2), 203, 2011.

22. VAZ E. de N., NIJKAMP P., PAINHO M., CAETANO M. A multi-scenario forecast of urban change: a study on urban growth in the Algarve. Landscape Urban Plan. 104, 201, 2012.

23. YUE W., LIU Y., FAN P. Measuring urban sprawl and its drivers in large Chinese cities: the case of Hangzhou. Land Use Policy. 31, 358, 2013.

24. ASCIONE M., CAMPANELLA L., CHERUBINI F., ULGIATI S. Environmental driving forces of urban growth and development an emergy-based assessment of the city of Rome, Italy. Landscape Urban Plan. 93, 238, 2009.

25. LIU S., GONG P. Change of surface cover greenness in China between 2000 and 2010. Chinese Sci. Bull. 57, (22), 2835, 2012.

26. AGUILERA-BENAVETE F., BOTEQUILHA-LEITÃO A., DIAZ-VARELA E. Detecting multi-scale urban growth patterns and processes in the Algarve region (Southern Portugal). Appl. Geogr. 53, 234, 2014.

27 Fuzhou Municipal Bureau of Statistics, Statistical yearbook of Fuzhou City. Beijing: China Statistical Press 2010 [In Chinese].

28. TAUBENBOCK H., WEGMANN M., ROTH A., MEHL H., DECH S. Urbanization in India - spatiotemporal analysis using remote sensing data. Comput. Environ. Urban 33, 179, 2009.

29. YOUSIF O., BAN Y. Improving urban change detection from multitemporal SAR images using PCA-NLM. IEEE T. Geosci. Remote 51, (4), 2032, 2013. 
30. ZHANG Q., BAN Y., HU Y., LIU J. The Trajectories of Urban Land and Industrial Land in Shanghai over the Past 30 Years. Jt. Urban Remote Sens. Event (JURSE), pp. 1-7, 2009.

31. LIU J., ZHANG Q., HU Y., Regional differences of China's urban expansion from late $20^{\text {th }}$ to early $21^{\text {st }}$ century based on remote sensing information. Chinese Geographical Science. 22, (1), 1, 2012.

32. TAVARES A. O., PATO R. L., MAGALHÃES M. C. Spatial and temporal land use change and occupation over the last half century in a peri-urban area. Appl. Geogr. 34, 432, 2012.

33. JONES N., de GRAAF J., RODRIGO I., DUARTE F. Historical review of land use changes in Portugal (before and after EU integration in 1986) and their implications for land degradation and conservation, with a focus on Centro and Alentejo regions. Appl. Geogr. 31, 1036, 2011.

34. China National Committee of Agricultural Divisions, Technical Regulation of Investigation on Land Use Status. Beijing: Surveying and Mapping Publishing House. 1984 [In Chinese].

35. BAN Y., YOUSIF O.A. Multitemporal spaceborne SAR data for urban change detection in China. IEEE J. Sel. Top. Applied Earth Observations and Remote Sensing 5, (4), 1087, 2012.

36. CAI Y. B., ZHANG H., PAN W. B., CHEN Y. H., WANG X. R. Urban Expansion and Its Influencing Factors in Natural Wetland Distribution Area in Fuzhou City, China. Chinese Geographical Science 22, (5), 568, 2012.

37. CAI Y. B., ZHANG H., PAN W. B., CHEN Y. H., WANG X. R. Land use pattern, socio-economic development, and assessment of their impacts on ecosystem service value: study on natural wetlands distribution area (NWDA) in Fuzhou city, southeastern China. Environ. Monit. Assess. 185, 5111, 2013.

38. WANG L., LI C., YING Q., CHENG X., WANG X., LI X., HU L., LINAG L., YU L., HUANG H., GONG P. China's urban expansion from 1990 to 2010 determined with satellite remote sensing. Chinese Sci. Bull. 57, (22), 2802, 2012.

39. ZHANG H., ZHOU L., CHEN M., MA W. Land use dynamics of the fast-growing Shanghai Metropolis, China (1979-2008) and its implications for land use and urban planning policy. Sensors 11, (2), 1794, 2011.

40. CHANDER G., MARKHAM B.L., HELDER D.L. Summary of current radiometric calibration coefficients for Landsat MSS, TM, ETM+, and EO-1 ALI sensors. Remote Sens. Environ. 113, (5), 893, 2009.
41. JASSEN I. F. L., FRANS J. M., WEL V. D. Accuracy assessment of satellite derived land-cover data: A review. Photogramm. Eng. Rem. S. 60, (4), 410, 1994.

42. PONTIUS Jr. R. G., MILLONES M. Death to Kappa: birth of quantity disagreement and allocation disagreement for accuracy assessment. Int. J. Remote Sens. 32, (15), 4407, 2011.

43. AGUILERA F., VALENZUELA L. M., BOTEQUILHA LEITÃO A. Landscape metrics in the analysis of urban land use patterns: a case study in a Spanish metropolitan area. Landscape Urban Plan. 99, (3-4), 226, 2011.

44. SUDHIRA H. S., RAMACHANDRA T. V., JAGADISH K. S. Urban sprawl: Metrics, dynamics and modelling using GIS. International Journal of Applied Earth Observation and Geoinformation 5, 29, 2004.

45. SCHWARZ N. Urban form revisited-selecting indicators for characterizing European cities. Landscape Urban Plan. 96, 29, 2010.

46. FRENKEL A., ASHKENAZI M. Measuring urban sprawl: how can we deal with it? Environ. Plann. B. 35, (1), 56, 2008.

47. YEH A. G., LI X. Measurement and monitoring of urban sprawl in a rapidly growing region using entropy. Photogramm. Eng. Rem. 67, 83, 2001.

48. LI X., YEH A. G. Analyzing spatial restructuring of land use patterns in a fast growing region using remote sensing and GIS. Landscape Urban Plan. 69, 335, 2004.

49. ZHANG Q., BAN Y., LIU J., HU Y. Simulation and analysis of urban growth scenarios for the Greater Shanghai area, China. Comput. Environ. Urban 35, (2), 126, 2011.

50. ZHANG H., QI Z. F., YE X. Y., CAI Y. B., MA W. C., CHEN M. N. Analysis of land use/land cover change, population shift, and their effects on spatiotemporal patterns of urban heat islands in metropolitan Shanghai, China. Appl. Geogr. 44, 121, 2013.

51. HAAS J., BAN Y. Urban growth and environmental impacts in Jing-Jin-Ji, the Yangtze, River Delta and the Pearl River Delta. International Journal of Applied Earth Observation and Geoinformation 30, 42, 2014

52. LI Y.-Y., ZHANG H., KAINZ W. Monitoring patterns of urban heat islands of the fast-growing Shanghai metropolis, China: Using time-series of Landsat TM/ETM+ data. International Journal of Applied Earth Observation and Geoinformation 19, 127, 2012. 
